\title{
Impact of influenza vaccine in reduction of incidence and severity of influenza-like illness
}

Ruhi Khan, ${ }^{1}$ Anwar Ahmed, ${ }^{1}$ Rachid Zeitounie ${ }^{1}$ and Rajiv Khandekar ${ }^{1}$

${ }^{1}$ King Khaled Eye Specialist Hospital, Riyadh, Saudi Arabia (Correspondence to: A. Ahmed: anwarahmed991@gmail.com).

\begin{abstract}
Background: Vaccination is useful for protection against seasonal influenza but has a low uptake. Evidence of a protective effect of influenza vaccine among Arab populations would be a useful tool for advocacy.

Aims: To evaluate the impact of vaccine in reducing the incidence and severity of influenza-like illness among health staff of a tertiary care eye hospital in Saudi Arabia.

Methods: This retrospective cohort study was conducted in 2018-2019. Hospital staff were divided into vaccinated and unvaccinated groups. Influenza-like illness episodes and their severity were compared between the groups and influenza-like illness rate before and after vaccination was reviewed in the vaccinated group.

Results: The uptake of flu vaccine among 1180 health staff was 41\%. There were 28 (9.3\%) and 51 (17\%) persons with influenza-like illness in the vaccinated $(n=300)$ and nonvaccinated $(n=300)$ groups, respectively. The nonvaccinated group had a significantly higher rate of influenza-like illness than the vaccinated group had. Vaccination, young age and absence of comorbidity were independent protectors against influenza-like illness.

Conclusions: Influenza vaccine confers significant protection and reduces the incidence and severity of influenza-like illness. However, this was a retrospective review of health data; therefore, the association of vaccine with outcomes should be considered as a weak form of evidence. The low uptake of influenza vaccine in hospital staff and their dependents is a matter of concern and should be addressed by greater awareness and education. This evidence can be used to improve overall vaccine coverage.

Keywords: influenza vaccine, influenza-like illness, airborne communicable diseases, respiratory infections, health workers

Citation: Khan R; Ahmed A; Zeitounie R; Khandekar R. Impact of influenza vaccine in reduction of incidence and severity of influenza-like illness. East Mediterr Health J. 2021;27(9):884-891. https://doi.org/10.26719/emhj.21.041

Received: 27/10/19; accepted: 04/02/21

Copyright (C) World Health Organization (WHO) 2021. Open Access. Some rights reserved. This work is available under the CC BY-NC-SA 3.o IGO license (https://creativecommons.org/licenses/by-nc-sa/3.o/igo)
\end{abstract}

\section{Introduction}

Influenza is a contagious viral illness that can cause severe morbidity and mortality. Each year up to 650000 deaths due to influenza are reported by the World Health Organization (WHO) (1). There are yearly epidemics of influenza due to changes in circulating virus undergoing mutations, emergence of multiple variants and lack of specific immunity in susceptible hosts (2). Hence, timely vaccination is crucial to prevent severe complications and mortality in communities.

Influenza-related complications include otitis media, pneumonia, exacerbation of chronic respiratory disease, neurological complications, and myocarditis (3). Adults with chronic illnesses are more vulnerable to influenza-related complications (3). Many viruses can cause respiratory illnesses similar to influenza, called influenza-like illness (ILI). The symptoms of ILI include fever, cough, sore throat and myalgia. Therefore, differentiating influenza from ILI without a laboratoryconfirmed test is challenging (4). According to WHO, ILI is the most predictive factor for influenza infection and seasonal variation of influenza activity.

Vaccination against influenza virus is used to decrease the severity and complications of respiratory illness and mitigate the risk of hospitalization $(5,6)$. Unfortunately, changes in the circulating influenza virus strains every year require new vaccines to provide virus-specific immunity (7). Influenza vaccination of health workers is a cost-effective approach that provides protection to frontline medical staff involved in the care and management of patients (8). In spite of educational programmes and public health initiatives in many countries, the vaccination rate continues to be less than desired $(33.2 \%)(9,10)$.

The annual Hajj pilgrimage in Saudi Arabia presents a unique challenge for controlling the spread of influenza. During the Hajj, pilgrims from many countries gather in a single region, posing a major risk for virus transmission and an influenza outbreak (11). While large mass gathering of many nationalities may be linked to influenza in the community, this study was undertaken after the completion of the 2018 Hajj season and did not overlap with the annual event. The Ministry of Health in Saudi Arabia therefore provides free vaccination to Saudi citizens and residents to protect against influenza virus circulating in the community, as well possible spread of disease emanating from influx of pilgrims. The uptake of these vaccinations is low in Saudi Arabia due to a 
negative attitude to immunization and possible lack of understanding of its benefits in the community (12).

In Saudi Arabia, the epidemiology of influenza during the 2018-2019 season included both influenza $A$ and $B$ viruses (13). While influenza A ( $\mathrm{H1N} 1)$ pdmog strain was predominant, other influenza A viruses (not subtyped) were also circulating earlier in the season. In contrast to the first half of 2018 when many cases of influenza $B$ were noted, the number of infections due to influenza B declined later in the year, with the virus lineage undetermined. This coincided with an increase in the incidence of influenza A during the influenza season. In 2019, the type of influenza viruses circulating in Saudi Arabia was similar to 2018, with influenza A(H1N1) pdmo9 being predominant compared to influenza $\mathrm{B}$ in earlier months. Other influenza A strains (not subtyped) were also circulating in the same period in 2019. This pattern was noted to be similar later in the season with increasing numbers of cases during October to December 2019. The vaccine provided by the Saudi Ministry of Health for the same season was a trivalent inactivated influenza virus vaccine with the following strains: Influenza $\mathrm{A} /$ Michigan/45/2015(H1N1) pdm-09 virus, Influenza A/ Singapore/INFIMH-16-0019/2016(H3N2)-like virus, and Influenza $\mathrm{B} /$ Colorado/06/2017-like virus (B/Victoria/2/87 lineage). Unfortunately, there are no national data in Saudi Arabia available to evaluate the extent of vaccine match with circulating viruses in the community.

The King Khaled Eye Specialist Hospital (KKESH) is a specialized tertiary eye hospital in Riyadh, Saudi Arabia. Hospital staff and their dependents are offered free vaccines before the influenza season. Influenza vaccination records are maintained electronically for each staff member and their dependents.To the best of our knowledge, there are no currently available studies evaluating the impact of influenza vaccination on the burden and severity of influenza in a healthcare setting in Saudi Arabia. Since influenza infection in hospital staff can have profound consequences for patients, we present the profile of ILI and its determinants among hospital staff and their dependents who were vaccinated against influenza compared to those who were not vaccinated during the 2018-2019 season.

\section{Methods}

The study was performed in compliance with the local heath authority ethical regulations and requirements and was approved by the Institutional Review Board of KKESH (R-19109023).

The study population comprised all staff at KKESH and their dependents enrolled with the Employee Health Department during the influenza season from October 2018 to March 2019. Only those who were or were not vaccinated in 2018 were included in the study. The study population was divided into vaccinated and unvaccinated groups and subjects were randomly selected for each group.
For the calculation of sample size, we estimated the number of health staff with ILI that would need active intervention. In the vaccinated group, it was assumed to be $20 \%$ of the total vaccinated and in the unvaccinated group, it was $41 \%$ of the total unvaccinated (14). To achieve $95 \%$ confidence interval (CI), 80\% power of a historical cohort study with a 1:1 ratio of vaccinated and unvaccinated individuals, we required a random selection of at least 268 vaccinated and 268 unvaccinated individuals. For logistic ease, we included 300 individuals in each group.

ILI was defined as fever $\geq 38^{\circ} \mathrm{C}$ and cough, with onset within the last 10 days (15). In addition to the aforementioned signs and symptoms, we also included cases with myalgia, dyspnea or pharyngitis, in the absence of another diagnosis (16). The severity of ILI was based on: (1) presence of tachycardia, abnormal oxygen saturation, and laboured breathing and adventitious breath sounds; (2) recommendation for further care at another referral hospital with specialized facilities; (3) provision of respiratory assistance therapy within KKESH and; (4) sick leave endorsed by a consultant physician for rest, time off work and to avoid the spread of ILI.

The retrospective chart (electronic medical record) review was performed to gather data on clinical and demographic variables including, age, gender, medical comorbidity (e.g., cardiac, pulmonary, neuromuscular, vascular or endocrine disease, or cancer), documented history of ILI during the current influenza season, severity of ILI, number of follow-up visits related to ILI, and sick leave.

The data were documented on a pretested data collection form and then transferred to an Access spreadsheet (Microsoft Corp., Redmond, WA, USA). Univariate analysis was performed using SPSS version 25 (IBM Corp., Armonk, NY, USA). Frequencies and percentage proportions were reported for qualitative data. Mean and standard deviations were reported for quantitative data. If the data were not normally distributed, the median and interquartile range were estimated. To compare the outcomes of vaccinated and unvaccinated groups, we calculated the difference of the means, the $95 \%$ CIs and the two-sided P values. For outcomes of qualitative variables, the relative risk, $95 \%$ $\mathrm{CI}$ and two-sided $P$ value were reported. If $>2$ subgroups were compared, $\chi^{2}$ value was estimated, along with degrees of freedom and $P$ value. Binominal regression analysis was performed to study the effect of age, gender and comorbidity on the association of vaccination to rate of ILI. The adjusted odds ratio (OR) was estimated, 95\% CI and two-sided $P$ value using OpenEpi stat calculator (17). $P<0.05$ was considered statistically significant.

\section{Results}

Among the study population of 1180 individuals in the Employee Health Department, KKESH, 489 (41\%) were vaccinated in 2018-2019. We randomly selected 300 people each from the vaccinated and unvaccinated groups. 
Their demographic characteristics and systemic comorbidities are compared in Table 1 . There were significantly more women in the vaccinated group compared to unvaccinated group.

There were 28 (9.3\%, 95\% CI 6.0-12.6\%) people with ILI among the vaccinated group compared with 51 (17\%, 95\% CI 12.7-21.3\%) in the unvaccinated group (Table 2). The vaccinated group had a significantly lower rate of ILI than the vaccinated group had (relative risk 0.7, 95\% CI 0.5-0.9, $P=0.006$ ). The rate of ILI according to different determinants is shown in Table 2 . The incidence of ILI was significantly lower in the vaccinated group $(P=0.005)$ and in people of young age $(P<0.001)$.

In the vaccinated group, $9(3 \%)$ people had symptoms only before vaccination, 15 (5\%) had symptoms only after vaccination, and $4(1.3 \%)$ had symptoms before as well as after vaccination. In the vaccinated group, $6(2 \%)$ people were given nebulization treatment. In the unvaccinated group, 12 (4\%) people underwent nebulization treatment in hospital and 2 at home. None of the cases (vaccinated and unvaccinated) had abnormal oxygen saturation. In the vaccinated group, the number of follow-up visits after initial presentation was $10(3.3 \%)$ compared with 21 (7\%) in the unvaccinated group. In the vaccinated group, 21 (7\%) were given sick leave compared with 44 (14.7\%) in the unvaccinated group.

We compared the impact of influenza vaccine in our study to that reported in literature (Table 3). Influenza vaccine reduces the risk of ILI, hospitalization and mortality related to influenza illness.

\section{Discussion}

In our study, the vaccine uptake was $48 \%$ among health staff of a tertiary care eye hospital in Saudi Arabia. We noted that influenza vaccination provided good protection against ILI in all age groups, and reduced the number of episodes and severity of ILI. The number of follow-up visits and absenteeism decreased considerably among vaccinated compared to unvaccinated individuals. Vaccination status, age and systemic comorbidity were independent risk factors for ILI. The ILI episodes before vaccination suggested that scheduling the vaccination in the earlier part of an epidemic season in our institute would be justified in future programmes.

The low uptake of vaccination among our study population is not a novel finding and has been shown in other reports. It was $<20 \%$ in an underprivileged community in the United States of America (18). Uptake of influenza vaccination ranging from $6 \%$ to $45 \%$ has been reported among the global adult population at low risk (19). This low uptake is of concern, and aggressive efforts are required to identify the responsible factors to improve vaccination rates. The clinical outcomes used to determine the impact of vaccination in protecting humans against ILI is a unique feature of this study. These clinical parameters can be applied to most developing countries with limited laboratories resources for confirming the diagnosis of influenza. The low uptake of vaccine among health staff has also been reported in other Arab populations (20). The impact of vaccination in reducing infectious diseases and their severity is not new and our study confirmed this universal observation. There are many published reports that favour vaccination to protect populations against severe complications of influenza and other infectious diseases (21).

The benefits of influenza vaccine in reducing mortality, morbidity, hospitalization and disease burden and costs for countries are undisputed, and it has been shown to be beneficial for elderly people and children (22-24). In a study from Taiwan, mortality in people aged > 65 years was lower in the group who received influenza vaccine. This was after adjusting for confounding factors (22). In another study, the efficacy of influenza vaccine in children was reviewed based on a meta-analysis of effectiveness of influenza vaccine in reducing the incidence of ILI or laboratoryconfirmed influenza. It was found that live influenza vaccines had higher efficacy in children (24). A German

Table 1 Profile of participants in influenza-like illness study

\begin{tabular}{|c|c|c|c|c|c|}
\hline & \multicolumn{2}{|c|}{$\begin{array}{l}\text { Vaccinated group } \\
\qquad(n=300)\end{array}$} & \multicolumn{2}{|c|}{$\begin{array}{l}\text { Nonvaccinated group } \\
\qquad(n=300)\end{array}$} & Validation \\
\hline \multicolumn{6}{|l|}{ Age, yr } \\
\hline Mean & \multirow{2}{*}{\multicolumn{2}{|c|}{$\begin{array}{l}38.2 \\
12.8\end{array}$}} & \multirow{2}{*}{\multicolumn{2}{|c|}{$\begin{array}{c}31.9 \\
9.0\end{array}$}} & Difference in mean 6.2 \\
\hline \multirow[t]{2}{*}{ SD } & & & & & $95 \%$ CI: $4.5-8.0, P<0.001$ \\
\hline & Number & Percentage & Number & Percentage & \\
\hline \multicolumn{6}{|l|}{ Gender } \\
\hline Male & 95 & 31.7 & 140 & 46.7 & $\mathrm{OR}=1.9,95 \%$ CI: $1.35-2.6$ \\
\hline Female & 205 & 68.3 & 160 & 53.3 & $P<0.001$ \\
\hline \multicolumn{6}{|c|}{ Systemic comorbidity } \\
\hline None & 236 & 78.7 & 274 & 91.3 & $\chi^{2}=25$ \\
\hline Cardiac & 0 & 0.0 & 3 & 1.0 & $\mathrm{df}=8$ \\
\hline Pulmonary & 23 & 7.7 & 13 & 4.3 & $P<0.001$ \\
\hline Neuromuscular & 3 & 1.0 & 2 & 0.7 & \\
\hline Vascular & 2 & 0.7 & 1 & 0.3 & \\
\hline Endocrine & 31 & 10.3 & 7 & 2.3 & \\
\hline Combination & 5 & 1.7 & 0 & 0.0 & \\
\hline
\end{tabular}

$\mathrm{CI}=$ confidence interval; $\mathrm{df}=$ degrees of freedom; $\mathrm{OR}=$ odds ratio; $\mathrm{SD}=$ standard deviation . 


\begin{tabular}{|c|c|c|c|c|c|}
\hline & \multicolumn{2}{|c|}{ ILI present $(n=79)$} & \multicolumn{2}{|c|}{ ILI not present $(n=521)$} & Validation \\
\hline \multirow{2}{*}{$\begin{array}{c}\text { Age, } \boldsymbol{y r} \\
\text { Mean } \\
\text { SD }\end{array}$} & \multicolumn{2}{|c|}{$\begin{array}{l}30.4 \\
10.7\end{array}$} & \multicolumn{2}{|c|}{$\begin{array}{l}35.8 \\
11.4\end{array}$} & \multirow[t]{2}{*}{$\begin{array}{l}\text { Difference in mean }=5.4 \\
(95 \% \text { CI: } 2.7-8.0) P<0.001\end{array}$} \\
\hline & Number & Percentage & Number & Percentage & \\
\hline \multicolumn{6}{|l|}{ Vaccination status } \\
\hline $\begin{array}{l}\text { Yes } \\
\text { No }\end{array}$ & $\begin{array}{l}28 \\
51\end{array}$ & $\begin{array}{l}35.4 \\
64.6\end{array}$ & $\begin{array}{l}272 \\
249\end{array}$ & $\begin{array}{l}52.2 \\
47.8\end{array}$ & $R R=0.7(95 \%$ CI: $0.5-0.9) P=0.005$ \\
\hline \multicolumn{6}{|l|}{ Gender } \\
\hline $\begin{array}{l}\text { Male } \\
\text { Female }\end{array}$ & $\begin{array}{l}34 \\
45\end{array}$ & $\begin{array}{l}43.0 \\
57.0\end{array}$ & $\begin{array}{l}201 \\
320\end{array}$ & $\begin{array}{l}38.6 \\
61.4\end{array}$ & $R R=1.1(95 \%$ CI: $0.8-1.5) P=0.5$ \\
\hline \multicolumn{6}{|l|}{ Comorbidity } \\
\hline $\begin{array}{l}\text { Present } \\
\text { Absent }\end{array}$ & $\begin{array}{l}63 \\
16\end{array}$ & $\begin{array}{l}79.7 \\
20.3\end{array}$ & $\begin{array}{c}446 \\
95\end{array}$ & $\begin{array}{l}85.6 \\
18.2\end{array}$ & $R R=0.96$ (95\% CI: 0.86-1.1) $P=0.6$ \\
\hline \multicolumn{6}{|c|}{ Type of principal comorbidity } \\
\hline None & 63 & 79.7 & 446 & 85.6 & \multirow{6}{*}{$\begin{array}{c}\chi^{2}=0.02 \\
\mathrm{df}=5 \\
\mathrm{P}=0.9\end{array}$} \\
\hline Cardiac & 1 & 1.3 & 3 & 0.6 & \\
\hline Pulmonary & 11 & 13.9 & 28 & 5.4 & \\
\hline Neuromuscular & 0 & 0.0 & 6 & 1.2 & \\
\hline Vascular & 1 & 1.3 & 2 & 0.4 & \\
\hline Endocrine & 3 & 3.8 & 35 & 6.7 & \\
\hline
\end{tabular}

$\mathrm{CI}=$ confidence interval; $\mathrm{d} f$ = degrees of freedom; $I L I=$ influenza-like illness; $O R=$ odds ratio; $R R=$ relative risk; $S D=$ standard deviation.

study reported that prior influenza vaccination was associated with less severe clinical course and improved overall long-term survival in patients with community acquired pneumonia during influenza seasons. (25). A surveillance data review confirmed the health benefits of vaccination in preventing influenza, related clinical visits and hospitalization (26). In European countries, gaps between vaccination coverage and recommendations resulted in higher influenza-related morbidity (27). Our findings are comparable with these studies; although the target population and methods used varied, the findings similarly suggest a gap between vaccination rates and public health recommendations.

In the current study, the health staff in the vaccinated group were older than in the unvaccinated group. Knowledge of the higher risk of complications of influenza in old age with greater systemic comorbidity among health staff could also occur in older individuals. The presence of comorbidity in a higher proportion of participants among the vaccinated group compared to

\begin{tabular}{|c|c|c|c|c|c|}
\hline Study no. & Authors & Location & Sample & Main findings & Refs \\
\hline 1 & Wang et al. & Taiwan & 35637 (age > 65 yr) & $\begin{array}{l}\text { Influenza vaccination reduces risk of major cause-specific } \\
\text { mortality in elderly population. }\end{array}$ & 22 \\
\hline 2 & Groenwold et al. & Netherland & $\begin{array}{l}50906 \text { periods of } \\
\text { observation }\end{array}$ & $\begin{array}{l}\text { Influenza vaccination reduced mortality risk in } 65 \text { years } \\
\text { and older in epidemic period compared to summer in } \\
\text { Netherlands }\end{array}$ & 23 \\
\hline 3 & Rhorer et al. & USA & 27000 children & $\begin{array}{l}\text { live attenuated influenza vaccine resulted in } 46 \% \text { fewer cases } \\
\text { of influenza illness in children }\end{array}$ & 24 \\
\hline 4 & Tessmer & Germany & 2368 patients & $\begin{array}{l}\text { Prior influenza vaccination was associated with less severe } \\
\text { clinical course and improved survival in patients with } \\
\text { community-acquired pneumonia in influenza seasons. }\end{array}$ & 25 \\
\hline 5 & Kostova et al. & USA & $\begin{array}{l}\text { Influenza illnesses } \\
\text { in } 6 \mathrm{yr}\end{array}$ & $\begin{array}{l}\text { Influenza vaccination programs in the US averted cases, } \\
\text { clinic visits and hospitalizations. }\end{array}$ & 26 \\
\hline 6 & Ryan et al. & 25 EU countries & $\begin{array}{l}\text { Population at risk of } \\
25 \text { EU countries }\end{array}$ & $\begin{array}{l}\text { Low influenza vaccination coverage in } 25 \text { European } \\
\text { countries increased morbidity, hospitalizations and } \\
\text { mortality associated with influenza-related complications. }\end{array}$ & 27 \\
\hline 7 & Bresee et al. & USA & Data of FluSurv-NET & $\begin{array}{l}\text { Influenza vaccination prevented } 6.6 \text { million influenza } \\
\text { illnesses and } 3.2 \text { million medically attended illnesses in } \\
2012-2013 \text { influenza season }\end{array}$ & 32 \\
\hline 8 & Reed et al. & USA & $\begin{array}{l}\text { Laboratory- } \\
\text { confirmed ILI } \\
\text { FluSurv-NET }\end{array}$ & $\begin{array}{l}\text { Influenza vaccination prevented approximately } 7.2 \text { million } \\
\text { illnesses, } 3.1 \text { million medically attended illnesses, and } 90000 \\
\text { hospitalizations associated with influenza in } 2013-2014\end{array}$ & 33 \\
\hline 9 & Present study & Saudi Arabia & $\begin{array}{l}600 \text { Saudi patients } \\
\text { attending clinic }\end{array}$ & $\begin{array}{l}\text { Influenza vaccinated group had reduced the number of } \\
\text { episodes and the severity of ILI. }\end{array}$ & - \\
\hline
\end{tabular}


unvaccinated group confirms this unique difference in comorbidities between groups. Thus, the higher protection noted among the influenza-vaccinated people with high risk of comorbidity could be an important finding to promote vaccination in the elderly population and people with other health conditions.

There was no significant gender difference in the rate of ILI despite a greater number of women in the vaccination group than in the unvaccinated group. A higher uptake for vaccination among women has also been observed by Simpson et al. (28). The underlying causes of this differential uptake should be investigated in order to devise gender-specific health promotional initiatives for greater outcomes. The similar rates of ILI between genders noted in our study is in contrast to Wang et al.(29), who reported a higher incidence among men.

The influenza vaccine in Saudi Arabia is supplied by the Ministry of Health and is available in 0.5-ml preloaded syringes (InfluVac*S; Abbot). For the 2018-2019 influenza season, it was supplied on 1 September 2018. Prior to this date, the vaccine for the southern hemisphere was provided to institutions in view of the influx of people and increased risk of virus transmission during the Hajj. The unit cost of influenza vaccine in Saudi Arabia is approximately US $\$ 10.00$ but is provided free at Ministry of Health institutions (including ours). In our institution, all staff and their dependents are encouraged to get vaccinated at the Employee Health Department.

There were some limitations to our study. This was a retrospective review of health data; therefore, the association of outcomes to the independent variables should be confirmed with prospective studies. Laboratory confirmation of clinically suspected ILI was not available due to lack of expertise and resources. The secondary indicators we used to determine the severity of ILI, such as respiratory support, leave certification and referral to other hospitals for further management, were influenced by a number of other factors. Hence these variables should be interpreted with caution before comparing our study to previous studies.
Some recent studies have investigated the attitudes and uptake of seasonal influenza vaccination in primary healthcare workers in Saudi arabia based on a questionnaire $(12,30,31)$. These studies concluded that vaccine coverage was suboptimal with knowledge gaps, misconceptions and hesitancy as major reasons. While these highlight a lack of understanding and the need for education as well as creating more awareness in healthcare providers, they were focused on primary healthcare settings. In contrast, our study population was unique as it was at higher risk of exposure to influenza infection because most were either working at a health facility or had a family member at risk of exposure to infection. We followed up this group of participants and evaluated whether there was a positive impact of influenza vaccination. Furthermore, we evaluated whether influenza vaccine curtailed episodes of ILI and its severity. These findings could be useful to promote periodic vaccination in the general population. The outcomes of this study support the strategy of the Saudi Ministry of Health for providing annual vaccinations in the preseason period. Our observations and conclusions are consistent with other reports that have suggested a need to increase research funding into influenza vaccines and undertake wider educational programmes in the Middle Eastern region (33).

In a number of developing countries in Asia, Latin America and Africa, laboratory molecular tests for diagnosis of ILI are limited for several reasons. A healthcare provider may largely be dependent on symptomatology in ILI cases for diagnosis of influenza. In the present study, we demonstrated the benefit of influenza vaccine in reducing the occurrence and severity of clinically diagnosed ILI. A clinical diagnosis of influenza may not be considered as best practice compared to laboratory-confirmed diagnosis. However, it could be useful as evidence to promote influenza immunization programmes, and increase their coverage and vaccine uptake in areas with limited resources.

Funding: None.

Competing interests: None declared.

\section{Impact du vaccin antigrippal sur la réduction de l'incidence et de la gravité du syndrome de type grippal}

\section{Résumé}

Contexte : La vaccination est utile pour se protéger contre la grippe saisonnière, mais son taux d'utilisation est faible. Démontrer l'effet protecteur du vaccin contre la grippe dans les populations arabes permettrait de mener des actions de sensibilisation.

Objectifs: Évaluer l'impact du vaccin sur la réduction de l'incidence et de la gravité du syndrome de type grippal (STG) parmi le personnel de santé d'un hôpital ophtalmologique de soins tertiaires en Arabie saoudite.

Méthodes : La présente étude de cohorte rétrospective a été menée en 2018-2019. Le personnel hospitalier a été divisé en groupes vaccinés et non vaccinés. Les épisodes de syndromes de type grippal et leur gravité ont été comparés entre les groupes et le taux de STG avant et après la vaccination a été examiné dans le groupe vacciné.

Résultats: Le taux d'utilisation du vaccin contre la grippe parmi les 1180 membres du personnel de santé était de $41 \%$. Les groupes vaccinés $(n=300)$ et non vaccinés $(n=300)$ comptaient respectivement $28(9,3 \%)$ et $51(17 \%)$ personnes atteintes de STG. Le groupe non vacciné présentait un taux de STG significativement plus 
élevé que celui du groupe vacciné. La vaccination, le jeune âge et l'absence de comorbidité constituaient des facteurs protecteurs indépendants contre le STG.

Conclusions: Le vaccin antigrippal confère une protection importante et réduit l'incidence et la gravité des STG. Cependant, il s'agit d'une étude rétrospective sur des données sanitaires; par conséquent, l'association du vaccin aux résultats devrait être considérée comme une preuve peu solide. La faible utilisation du vaccin contre la grippe par le personnel hospitalier et les personnes à leur charge est préoccupante et devrait être traitée par une sensibilisation et une éducation accrues. Ces données peuvent être utilisées pour améliorer la couverture vaccinale globale.

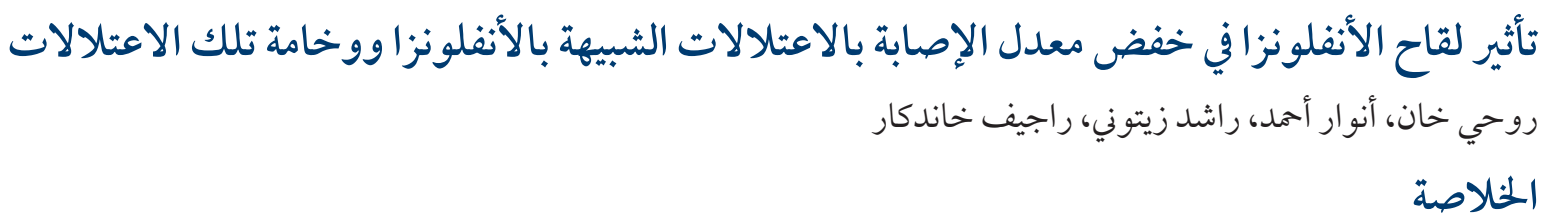

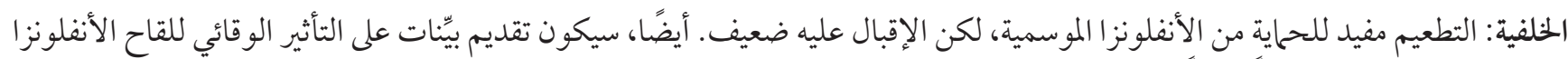
بين سكان البلدان العربية أداةً مفيدةً للدعوة إلى التفلئل التطعيم.

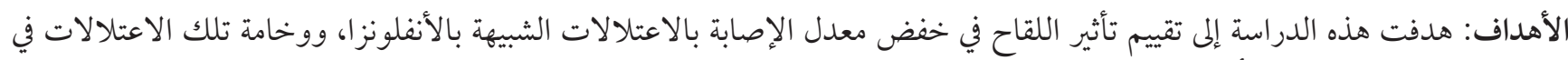

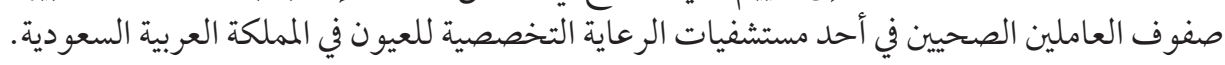
طُرق البحث: أُجريت هذه الدراسة الأترابية الاسترجاعية في الفترة بين عامئ

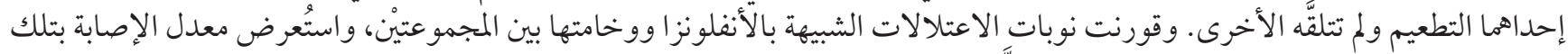

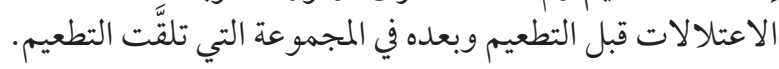

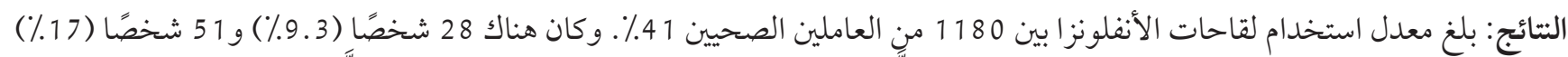

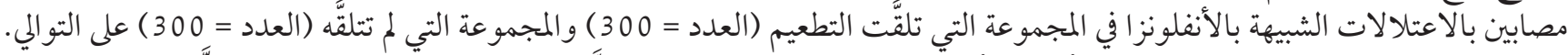

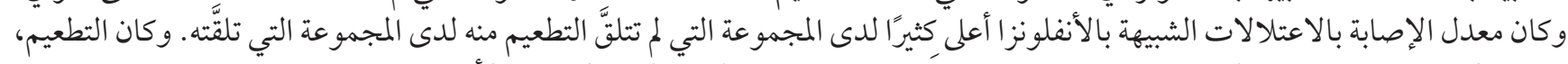

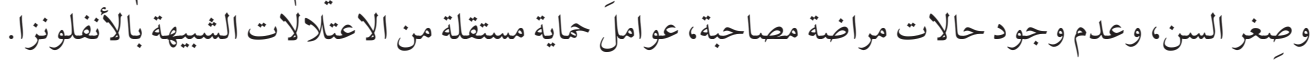

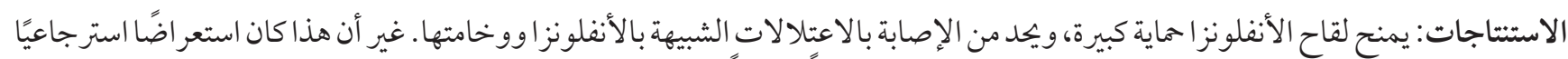

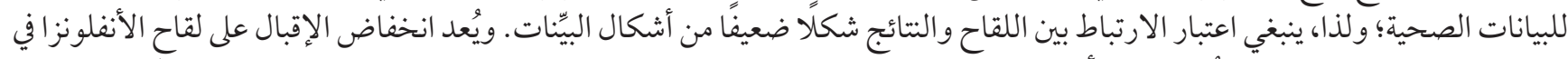

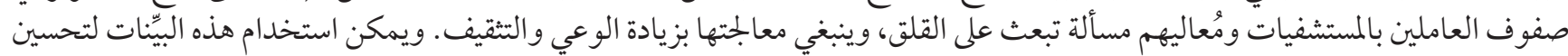
التغطية الشاملة باللقاحات.

\section{References}

1. Influenza. Burden of disease. Estimate of influenza death due to respiratory disease. Geneva: World Health Organization (https://www.who.int/influenza/surveillance_monitoring/bod/WHO-INFLUENZA-MortalityEstimate.pdf?ua=1).

2. Goka EA, Vallely PJ, Mutton KJ, Klapper PE. Mutations associated with severity of the pandemic influenza A (H1N1) pdmog in humans: a systematic review and meta-analysis of epidemiological evidence. Arch Virol. 2014 Dec;159(12):3167-83. https://doi. org/10.1007/s00705-014-2179-z PMID:25078388

3. Flu symptoms \& complications [website]. Atlanta: Centers for Disease Control and Prevention (https://www.cdc.gov/flu/symptoms/symptoms.htm, accessed 27 April 2021).

4. Jefferson T, Rivetti A, Di Pietrantonj C, Demicheli V. Vaccines for preventing influenza in healthy children. Cochrane Database Syst Rev. 2018 Feb 1;2(2):CDo04879. https://doi.org/10.1002/14651858.CD004879.pub5. PMID:29388195

5. Rondy M, El Omeiri N, Thompson MG, Levêque A, Moren A, Sullivan SG. Effectiveness of influenza vaccines in preventing severe influenza illness among adults: a systematic review and meta-analysis of test-negative design case-control studies. J Infect. 2017 Nov;75(5):381-94. https://doi.org/10.1016/j.jinf.2017.09.010 PMID:28935236

6. Thompson MG, Pierse N, Huang QS, Prasad N, Duque J, Newbern EC, et al. Influenza vaccine effectiveness in preventing influenza-associated intensive care admissions and attenuating severe disease among adults in New Zealand 2012-2015. Vaccine. 2018 Sep 18;36(39):5916-25. https://doi.org/10.1016/j.vaccine.2018.07.028 PMID:30077480

7. How the flu virus can change [website]. Atlanta: Centers for Disease Control and Prevention (https://www.cdc.gov/flu/about/ viruses/change.htm, accessed 27 April 2021).

8. Imai C, Toizumi M, Hall L, Lambert S, Halton K, Merollini K. A systematic review and meta-analysis of the direct epidemiological and economic effects of seasonal influenza vaccination on healthcare workers. PloS One. 2018 Jun 7;13(6):e0198685. https:// doi.org/10.1371/journal.pone.0198685 PMID:29879206 
9. Casalino E, Ghazali A, Bouzid D, Antoniol S, Pereira L, Kenway P. Emergency Department study group on respiratory viruses. Patient's behaviors and missed opportunities for vaccination against seasonal epidemic influenza and evaluation of their impact on patient's influenza vaccine uptake. PLoS One. 2018 Mar 22;13(3):e0193029. https://doi.org/10.1371/journal.pone.0193029 PMID:29565990

10. Jorgensen P, Mereckiene J, Cotter S, Johansen K, Tsolova S, Brown C. How close are countries of the WHO European Region to achieving the goal of vaccinating $75 \%$ of key risk groups against influenza? Results from national surveys on seasonal influenza vaccination programmes, 2008/2009 to 2014/2015. Vaccine. 2018 Jan 25;36(4):442-52. https://doi.org/10.1016/j.vaccine.2017.12.019 PMID:29287683

11. Shirah BH, Zafar SH, Alferaidi OA, Sabir AM. Mass gathering medicine (Hajj Pilgrimage in Saudi Arabia): the clinical pattern of pneumonia among pilgrims during Hajj. J Infect Public Health. 2017 May-Jun;10(3):277-86. https://doi.org/10.1016/j. jiph.2016.04.016 PMID:27262693

12. Alabbad AA, Alsaad AK, Al Shaalan MA, Alola S, Albanyan EA. Prevalence of influenza vaccine hesitancy at a tertiary care hospital in Riyadh, Saudi Arabia. J Infect Public Health. 2018 Jul-Aug;11(4):491-9. https://doi.org/10.1016/j.jiph.2017.09.002 PMID:28988776

13. FluNet [website]. Geneva: World Health Organization (http://www.who.int/influenza/gisrs_laboratory/flunet/en/, accessed 27 April 2021).

14. Nichols MK, Andrew MK, Ye L, Hatchette TF, Ambrose A, Boivin G, et al. The impact of prior season vaccination on subsequent influenza vaccine effectiveness (VE) to prevent influenza-related hospitalizations over four influenza seasons in Canada. Clin Infect Dis. 2019 Aug 30;69(6):970-9 https://doi.org/10.1093/cid/ciy1009 PMID:30508064

15. Fitzner J, Qasmieh S, Mounts AW, Alexander B, Besselaar T, Briand S, et al. Revision of clinical case definitions: influenza-like illness and severe acute respiratory infection. Bull World Health Org. 2018 Feb 1;96(2):122-8. https://doi.org/10.2471/BLT.17.194514 PMID:29403115

16. Adler AJ, Eames KT, Funk S, Edmunds WJ. Incidence and risk factors for influenza-like-illness in the UK: online surveillance using Flusurvey. BMC Infect Dis. 2014 May 1;14(1):232. https://doi.org/10.1186/1471-2334-14-232 PMID:24885043

17. Dean AG, Sullivan KM, Soe MM. OpenEpi: open source epidemiologic statistics for public health, version 2.3.1 [website] (www. OpenEpi.com, accessed 27 April 2021).

18. Redelings MD, Piron J, Smith LV, Chan A, Heinzerling J, Sanchez KM, et al. Knowledge, attitudes, and beliefs about seasonal influenza and $\mathrm{H} 1 \mathrm{~N} 1$ vaccinations in a low-income, public health clinic population. Vaccine. 2012 Jan 5;30(2):454-8. https://doi. org/10.1016/j.vaccine.2011.10.050 PMID:22044740

19. Yeung MP, Lam FL, Coker R. Factors associated with the uptake of seasonal influenza vaccination in adults: a systematic review. J Public Health. 2016 Dec 2;38(4):746-53. https://doi.org/10.1093/pubmed/fdv194 PMID:28158550

20. Alqahtani AS, Bondagji DM, Alshehari AA, Basyouni MH, Alhawassi TM, BinDhim NF, et al. Vaccinations against respiratory infections in Arabian Gulf countries: Barriers and motivators. World J Clin Cases. 2017 Jun 16;5(6):212-21. https://doi.org/10.12998/ wjcc.v5.i6.212 PMID:28685134

21. Arriola C, Garg S, Anderson EJ, Ryan PA, George A, Zansky SM, et al. Influenza vaccination modifies disease severity among community-dwelling adults hospitalized with influenza. Clin Infect Dis. 2017 Oct 15;65(8):1289-97. https://doi.org/10.1093/cid/ cix468 PMID:28525597

22. Wang CS, Wang ST, Lai CT, Lin LJ, Chou P. Impact of influenza vaccination on major cause-specific mortality. Vaccine. 2007 Jan 26;25(7):1196-203. https://doi.org/10.1016/j.vaccine.2006.10.015 PMID: 17097773

23. Groenwold RH, Hoes AW, Hak E. Impact of influenza vaccination on mortality risk among the elderly. Eur Resp J. 2009 Jul;34(1):56-62. https://doi.org/10.1183/09031936.00190008 PMID:19213779

24. Lukšić I, Clay S, Falconer R, Pulanić D, Rudan I, Campbell H, et al. Effectiveness of seasonal influenza vaccines in children - a systematic review and meta-analysis. Croatian Med J. 2013 Apr;54(2):135-45. https://doi.org/10.3325/cmj.2013.54.135 PMID:23630141

25. Tesmer A, Welte T, Schmit-Ott R, Eberle S, Barten G, Suttorp N, et al. Influenza vaccination is associated with reduced severity of community-acquired pneumonia. European Respiratory Journal. 2011 Jul;38(1):147-53. https://doi.org/101183/09031936.00133510 PMID:21148226

26. Kostova D, Reed C, Finelli L, Cheng PY, Gargiullo PM, Shay DK, et al. Influenza illness and hospitalizations averted by influenza vaccination in the United States, 2005-2011. PloS One. 2013 Jun 19;8(6):e66312. https://doi.org/10.1371/journal.pone.0066312 PMID:23840439

27. Ryan J, Zoellner Y, Gradl B, Palache B, Medema J. Establishing the health and economic impact of influenza vaccination within the European Union 25 countries. Vaccine. 2006 Nov 17;24(47-48):6812-22. https://doi.org/10.1016/j.vaccine.2006.07.042 PMID:17034909

28. Simpson CR, Lone N, Kavanagh K, Ritchie LD, Robertson C, Sheikh A, et al. Seasonal Influenza Vaccine Effectiveness (SIVE): an observational retrospective cohort study -exploitation of a unique community-based national-linked database to determine the effectiveness of the seasonal trivalent influenza vaccine. Health Services and Delivery Research. Southampton: NIHR Journals Library. https://doi.org/10.3310/hsdro1100 PMID:25642510

29. Wang XL, Yang L, Chan KH, Chan KP, Cao PH, Lau EH, et al. Age and sex differences in rates of influenza-associated hospitalizations in Hong Kong. Am J Epidemiol. 2015 Aug 15;182(4):335-44. https://doi.org/10.1093/aje/kwvo68 PMID:26219977 
30. Awadalla NJ, Al-Musa HM, Al-Musa KM, Asiri AM, Albariqi AA, Majrashi HM, et al. Seasonal influenza vaccination among primary health care workers in Southwestern Saudi Arabia. Hum Vaccin Immunother. 2020;16(2):321-6. https://doi.org/10.1080/2164 5515.2019.1666500 PMID:31526228

31. Alsuhaibani M. Barriers and beliefs among health-care workers regarding seasonal influenza vaccine in Al-Qassim region, Saudi Arabia. Hum Vaccin Immunother. 2020;16(2):313-20. https://doi.org/10.1080/21645515.2019.1656020 PMID:31424315

32. Zaraket H, Melhem N, Malik M, Khan WM, Dbaibo G, Abubakar A. Review of seasonal influenza vaccination in the Eastern Mediterranean Region: policies, use and barriers. J Infect Public Health. 2019;12(4):472-8. https://doi.org/10.1016/j. jiph.2018.10.009 PMID:30446255

33. Reed C, Kim IK, Singleton JA, Chaves SS, Flannery B, Finelli L, et al. Centers for Disease Control and Prevention (CDC). Estimated influenza illnesses and hospitalizations averted by vaccination--United States, 2013-14 influenza season. MMWR Morb Mortal Wkly Rep. 2014 Dec 12;63(49):1151. https://doi.org/10.1093/cid/ciz676 PMID: 25503917 